\title{
Preparation and Performance of Catalytic Hollow Fibre Membranes for Hydrogenation Reduction of Nitrites in Water
}

\author{
Gonghe Tong ${ }^{\mathrm{a}}$, Jian Song ${ }^{\mathrm{a}}$, Peng Wang ${ }^{\mathrm{b}}$, Hongyong Zhao a and Xiaoyao Tan ${ }^{\mathrm{a},{ }^{*}}$
}

${ }^{a}$ The State Key Laboratory of Hollow Fiber Membrane Materials and Processes, Department of Chemical Engineering, Tianjin Polytechnic University, Tianjin 300387, China

${ }^{b}$ Shandong Yuanming Biotechnology Co. Ltd., Weifang 262700, China

\begin{abstract}
Porous $\mathrm{Al}_{2} \mathrm{O}_{3}$ hollow fiber membranes have been fabricated via a phase inversion - sintering technique. Pdloaded carbon nanotubes (CNTs) are formed inside the hollow fibre wall by the catalytic decomposition of methane over Fe particles, followed by impregnation and reduction with hydrogen to form catalytic hollow fibre membranes. Hydrophobic modification of the hollow fibres is conducted by gas permeable polymeric coating. The resultant hollow fibre membranes exhibit highly catalytic activity to the hydrogenation reduction of nitrites in aqueous solution. Hollow fibre membrane reactors are assembled for nitrite hydrogenation by pumping nitrite solution into the tube side and introducing hydrogen countercurrently to the shell side of the reactor. The nitrite removal in the hollow fibre membrane reactors increases with the operation temperature and the hydrogen feed concentration at lower hydrogen partial pressures, but less influenced by the hydrogen feed concentration when it is higher than $50 \%$. A higher nitrite concentration favors the nitrite hydrogenation reaction but lowers the nitrite removal efficiency.
\end{abstract}

Keywords: Hollow fibre, catalytic membrane reactor, nitrite removal, hydrogenation reduction.

\section{INTRODUCTION}

The removal of nitrites $\left(\mathrm{NO}_{2}^{-}\right)$and nitrates $\left(\mathrm{NO}_{3}^{-}\right)$ from water is environmentally important since these contaminants can cause cancer thus extremely harmful to human health $[1,2]$. The elimination of these nitrite/nitrates can be in principle achieved by using a conventional physicochemical method like ion exchange, reverse osmosis and electrodialysis, or a biological method. The main disadvantage of the physicochemical methods is to produce a secondary waste stream while the biological denitrification processes have low reaction rates, making them insufficient for ground/surface water treatment. In order to overcome these shortcomings, a catalytic hydrogenation reduction route has been developed in which the nitrite ions are converted on a noble-metal solid catalyst to nitrogen $\left(\mathrm{N}_{2}\right)$ and/or ammonia as a byproduct at ambient temperature [3].

$$
\begin{aligned}
& \mathrm{NO}_{3}^{-}+\mathrm{H}_{2} \stackrel{\mathrm{P}_{d}-\mathrm{Cu}}{\longrightarrow} \mathrm{NO}_{2}^{-}+\mathrm{H}_{2} \mathrm{O} \\
& 2 \mathrm{NO}_{2}^{-}+3 \mathrm{H}_{2} \stackrel{P_{d}}{\longrightarrow} \mathrm{N}_{2}+2 \mathrm{OH}^{-}+2 \mathrm{H}_{2} \mathrm{O} \\
& 2 \mathrm{NO}_{2}^{-}+6 \mathrm{H}_{2} \stackrel{P_{d}}{\longrightarrow} 2 \mathrm{NH}_{4}^{+}+4 \mathrm{OH}^{-}
\end{aligned}
$$

This reaction system has fast kinetics and is generally limited by the internal diffusion in catalysts.

\footnotetext{
*Address correspondence to this author at the State Key Laboratory of Hollow Fiber Membrane Materials and Processes, Department of Chemical Engineering, Tianjin Polytechnic University, Tianjin 300387, China; Tel:+86 22 83955663; Fax: +86 22 83955663; E-mail: tanxiaoyao@tjpu.edu.cn
}

Therefore, any attempts to promote the accessibility of the catalyst support materials such as minimizing the particles size and tortuosity, or maximizing the porosity would improve the catalytic activity as well as selectivity to nitrogen $[4,5]$. To date, the catalytic hydrogenation of nitrite and nitrate for water purification has been examined extensively to develop efficient catalysts. For example, a thin layer of entangled carbon nanofibers (CNFs) prepared on structured supports enables to avoid slurry phase operation and to optimize hydrodynamics and gas-liquid mass transfer $[6,7]$.

In addition to the development of efficient catalysts, numerous studies have exploited to achieve large gasliquid contacting interface for gas-liquid-solid (G-L-S) processes. The varieties of reactors for the heterogeneously catalyzed gas-liquid-solid systems include slurry reactors, bubble or spray columns, agitated tanks and trickle-bed reactors. Catalytic membrane reactors can be applied for G-L-S reactions and have advantages over conventional three-phase reactors. Catalytically active components are deposited on the porous membrane. Gas is permeated through the membrane and dissolved in the liquid phase that is fed through the support to the catalytic layer from the other side of the membrane. Thereby, an effective contact between the gas-liquid reactants and the solid catalyst is established. Alternatively, it also can be operated by pumping the dissolved reactants through the catalytic membrane, thus a very short contact time can be achieved. This implies that the membrane reactors can provide an efficient gas-liquid contacting interface between the gas 
and liquid phases therefore minimizing the mass transfer limitations $[8,9]$.

In this work, porous $\mathrm{Al}_{2} \mathrm{O}_{3}$ ceramic hollow fiber membranes deposited with carbon nano-tubes (CNTs) as the solid catalyst carrier were fabricated for hydrogenation reduction of nitrites in water. The hollow fiber membrane configuration is applied because of the high surface to volume ratio and the reduced mass transfer limitations. CNTs are utilized as catalyst supports in view of the strong mechanical structure, high specific surface area and low tortuosity. A catalytic hollow fiber membrane reactor was assembled for the removal of nitrites in water. The performances of the reactor have been evaluated in terms of the nitrite conversions at various operating conditions.

\section{EXPERIMENTAL}

\subsection{Preparation of $\mathrm{Al}_{2} \mathrm{O}_{3}$ Hollow Fibres}

$\mathrm{Al}_{2} \mathrm{O}_{3}$ ceramic hollow fibers were fabricated via a phase inversion and sintering technique [10, 11]. An alumina suspension consisting of $64.5 \mathrm{wt} \% \quad \alpha-\mathrm{Al}_{2} \mathrm{O}_{3}$ powder with the particle diameter of $\sim 1 \mu \mathrm{m}, 7.2 \mathrm{wt} \%$ polyethersulfone (PES, Radel A-300) (binder), 27.3 wt\% N-methyl-2-pyrrolidone (NMP) (solvent) and 1.0 wt $\%$ polyvinylpyrrolidone (PVP, K90, $\mathrm{M}_{\mathrm{w}}=630,000$ ) (additive)was prepared. The prepared suspension was degassed by applying vacuum for $1 \mathrm{~h}$ and left overnight under dry air. The spinning mixture was then transferred to a stainless steel vessel and consequently extruded through a tube-in-orifice spinneret (inner and outer diameter of $1.5 / 3.0 \mathrm{~mm}$, respectively) into a tap water bath. The air gap was $2 \mathrm{~cm}$ and de-ionized (DI) water was pressed through the bore of the spinneret. The fibers were kept in a water bath for 1 day for removal of the NMP and consequently dried for 1 day. Finally, the hollow fibre precursors were sintered at $1500^{\circ} \mathrm{C}$ for $4 \mathrm{~h}$ in stagnant air to allow the fusion and bonding to occur. The prepared $\mathrm{Al}_{2} \mathrm{O}_{3}$ hollow fibre membranes had dimensions of 2.3/1.7 mm in o.d./i.d.

\subsection{Preparation of Catalytic Hollow Fibre Membranes}

The preparation of the catalytic hollow fibre membranes consisted of 4 stages, as illustrated in Figure 1. The details of the protocol are described as follows.

(1) Iron-catalyst deposition. Iron (Fe) was used as the catalyst for growth of carbon nanotubes inside the $\mathrm{Al}_{2} \mathrm{O}_{3}$ hollow fibres [12]. The $\mathrm{Al}_{2} \mathrm{O}_{3}$ hollow fibre samples were immersed into boiling water in a glass vessel. $\mathrm{FeCl}_{3}$ solution $(5.6 \mathrm{~mol} / \mathrm{L})$ was added dropwise into the glass vessel until ferrous hydroxide colloids were obtained, re-dispersed into the ceramic hollow fibers. The samples were removed from the colloids and dried at $50^{\circ} \mathrm{C}$ in air overnight. Finally the samples were calcined at $400^{\circ} \mathrm{C}$ in air for $1 \mathrm{~h}$ followed by a $2 \mathrm{~h}$ reduction treatment with hydrogen at the same temperature. The weight increase after the Fe-catalyst deposition was about $2.3 \mathrm{wt} \%$.

(2) Growth of carbon nanotubes (CNTs). Carbon nanotubes were produced by the chemical vapor deposition method (CVD) of methane on the $\mathrm{Fe}$ deposited $\mathrm{Al}_{2} \mathrm{O}_{3}$ hollow fibres [13-16]. The $\mathrm{Fe}$ impregnated hollow fibres were placed in a quartz tube located in a furnace. Methane was introduced into the quartz tube at a flow rate of $30 \mathrm{~mL} / \mathrm{min}$ while the temperature was increased to $700{ }^{\circ} \mathrm{C}$ with a heating ramp of $10{ }^{\circ} \mathrm{C} / \mathrm{min}$ for methane decomposition. The CNTs formation reaction was performed for $1 \mathrm{~h}$, and ended by flowing nitrogen until the system was cooled to room temperature. After CNTs formation, the hollow fibres were immersed in concentrated nitric acid for $5 \mathrm{~h}$ to remove the iron particles, followed by ultrasonic washing with DI water. Finally, the samples were dried at $100{ }^{\circ} \mathrm{C}$ under vacuum overnight and weighted to evaluate the CNTs loading in the $\mathrm{Al}_{2} \mathrm{O}_{3}$ hollow fibres.

(3) Palladium deposition. For Pd catalyst deposition, the CNTs loaded hollow fibres were
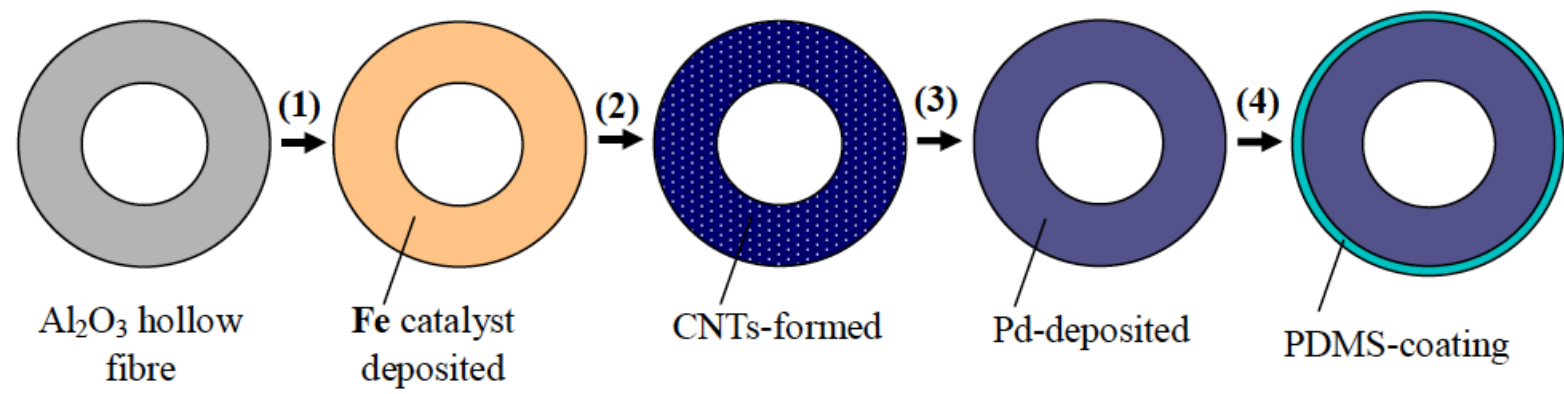

PDMS-coating

Figure 1: Preparation steps of the catalytic hollow fibre membranes. 
immersed into a palladium precursor solution containing $300 \mathrm{mg}$ palladium(II) 2,4-pentanedione $\left(\mathrm{Pd}(\mathrm{acac})_{2}\right.$; Aladdin, 34.9\%) in $50 \mathrm{~mL}$ toluene for $24 \mathrm{~h}$. The samples were taken out from the solution, dried at $50^{\circ} \mathrm{C}$ overnight, calcined at $350^{\circ} \mathrm{C}$ in $\mathrm{N}_{2}$ for $1 \mathrm{~h}$ and finally reduced in $\mathrm{H}_{2}$ at the same temperature for $1 \mathrm{~h}$. This operation was repeated 3 times to promote the palladium $(\mathrm{Pd})$ content in the hollow fibres. Measurement of the difference in weight before and after Pd-deposition showed that the $\mathrm{Pd}$ catalyst deposited in the membrane was about 0.96 wt\%.

(4) PDMS coating. The hollow fiber membranes were hydrophobized by PDMS-coating on the outer surface. Momentive PDMS RTV 615 kit (purchased from Wenhao Chip Technology) consisting of vinylterminated pre-polymer (RTV-A) and Pt-catalyzed cross-linker (RTV-B) was dissolved in cyclohexane in a concentration of $10 \%(\mathrm{w} / \mathrm{w})$. The pre-cross-linking reaction was conducted at $60^{\circ} \mathrm{C}$ for $1 \mathrm{~h}$. For surface modification (hydrophobization), the hollow fiber samples sealed at both ends with glue were dip-coated in the cross-linked PDMS solution, and then heated at $60^{\circ} \mathrm{C}$ in an oven overnight to finalize the cross linking reaction. Contact angle measurement was actualized to confirm the hydrophobicity of the outer surfaces.
For comparison, direct carbonization of glucose was also applied to form carbon inside the $\mathrm{Al}_{2} \mathrm{O}_{3}$ hollow fibres. The $\mathrm{Al}_{2} \mathrm{O}_{3}$ hollow fibres were soaked in saturated glucose solution for $1 \mathrm{~h}$, accompanied by calcination at $400^{\circ} \mathrm{C}$ in nitrogen atmosphere to complete carbon deposition.

\subsection{Nitrite Hydrogenation in Hollow Fibre Membrane Reactors}

Figure 2 shows the experimental setup for nitrite hydrogenation in the catalytic hollow fibre membrane reactor. A hollow fibre with a length of $17 \mathrm{~cm}$ was housed in a quartz tube with epoxy as the sealant on both ends of the reactor. Nitrite solution was pumped from the solution tank into the tube side while hydrogen $\left(\mathrm{H}_{2}\right)$ was fed counter currently to the shell side of the reactor. The nitrite $\left(\mathrm{NO}_{2}{ }^{-}\right)$concentration was sampled from the solution tank and measured as a function of operation time using ultraviolet (UV) spectrophotometer (Purkinje General, TU-1901). Figure 3 shows the relationship between the UV absorbance of the nitrite solution and the standard $\mathrm{NO}_{2}^{-}$ion concentration. The correlation coefficient, $\mathrm{R}^{2}$ value higher than 0.999 , suggests a good linear relationship between them in the measurement range. The nitrite removal was calculated by the following equation,

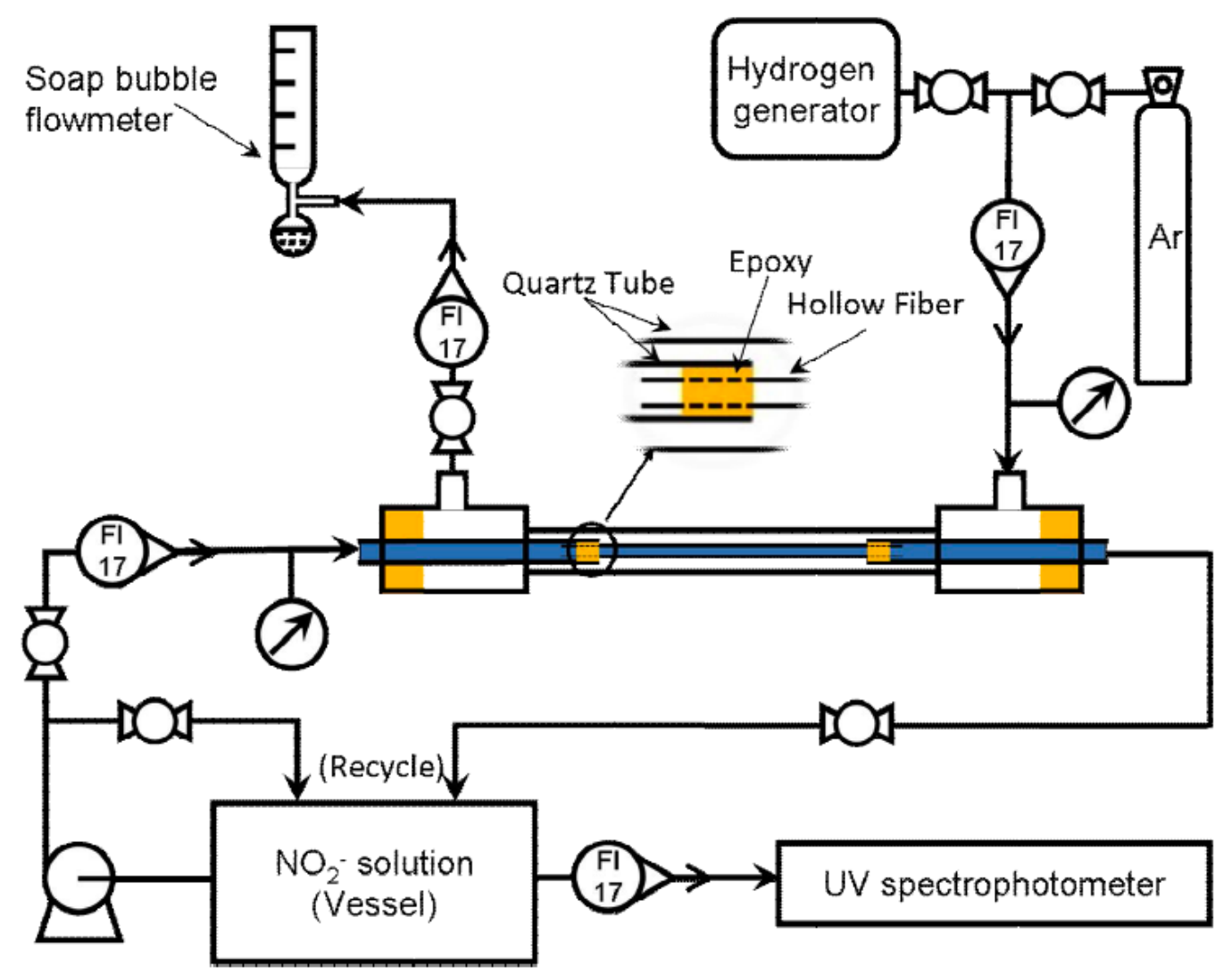

Figure 2: Schematic representation of the experimental setup. 


$$
X=\left(1-\frac{C}{C_{0}}\right) \times 100 \%
$$

where $C$ and $C_{0}$ are the measured and initial nitrite concentrations in the feed vessel, $\mathrm{mg} \mathrm{L}^{-1}$.

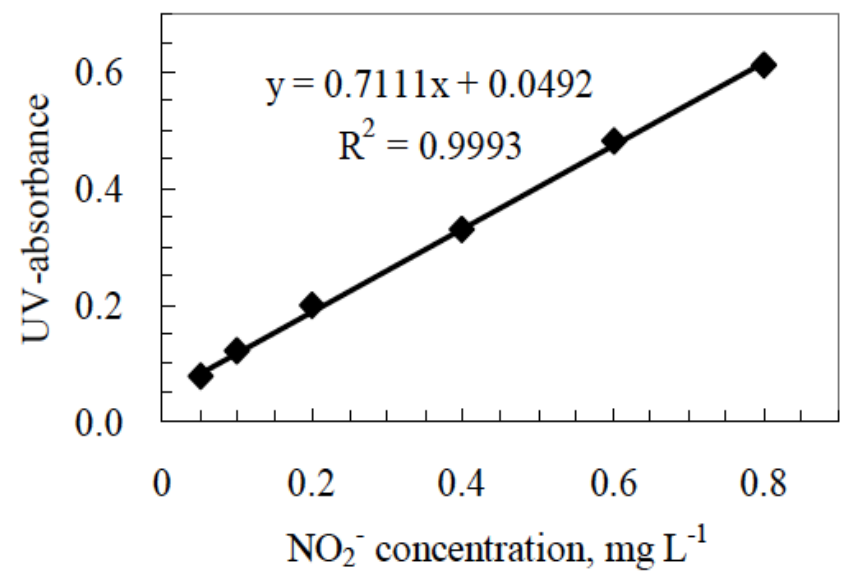

Figure 3: Relationship between the UV absorbance and the $\mathrm{NO}_{2}^{-}$ion concentration in standard solution.

\subsection{Characterization}

The morphology and structure of the hollow fibres were visually observed using a Scanning Electron Microscopy (SEM, Hitachi Ltd., S-4800). The samples were sputtered with a thin gold layer before imaging. Hitachi-S-4800 analyzer coupled to the SEM was employed for rapid EDX analysis of chemical compositions. The incident electron beam impinging the sample surface from normal angle and controlled the energies ranged from 3 to $20 \mathrm{keV}$. Both TEM micrographs and TEM-EDX analysis of the samples were carried out with JEM-2100F transmission electron microscope (JEOL) with acceleration voltage of $200 \mathrm{kV}$.

\section{RESULTS AND DISCUSSION}

\subsection{Morphology of the Catalytic Hollow Fibre Membranes}

Morphology of the catalytic ceramic hollow fibre membranes is shown in Figure 4. As can be seen, the $\mathrm{Al}_{2} \mathrm{O}_{3}$ hollow fibre exhibits an obvious asymmetric structure which was formed during the phase inversion process $[10,11]$. The outer/inner diameters of the hollow fibre membranes are measured to be ca. 2.3/1.7 $\mathrm{mm}$. The thickness of the PDMS coating on the outer surface of the hollow fiber is around $20 \mu \mathrm{m}$, as is shown in Figure $\mathbf{4 b}$. The contact angle measured on the outer-layer of the fibres was around $135.8^{\circ}$, mirroring that the hydrophobic membrane outer surface helps to prevent the exudation of liquid solution.

Figure 5 shows the carbon nano-tubes (CNTs) formed inside the pores of the catalyst-loaded $\mathrm{Al}_{2} \mathrm{O}_{3}$ hollow fibre membranes. The diameter of the CNTs was around $30 \mathrm{~nm}$ (Figure 5b) and the weight increase due to the CNTs growth was measured to be about 0.64 wt \%. The tubular structure of the CNTs can be more clearly seen in the TEM images presented in Figure 5c. Further, the Pd distribution on the CNTs was also measured, as shown in Figure $\mathbf{5 d}$. The immobilized Pd particles are fairly even in size and also dispersed quite uniformly on the CNTs support.

\subsection{Membrane Reactor Performances in Nitrate Removal}

In order to evaluate the performance of the catalytic hollow fibre membrane reactors, the initial volume of nitrite solution in the tank was fixed at $330 \mathrm{~mL}$ for each experiment, and the $\mathrm{NO}_{2}^{-}$concentration in the tank solution was measured as a function of time at different

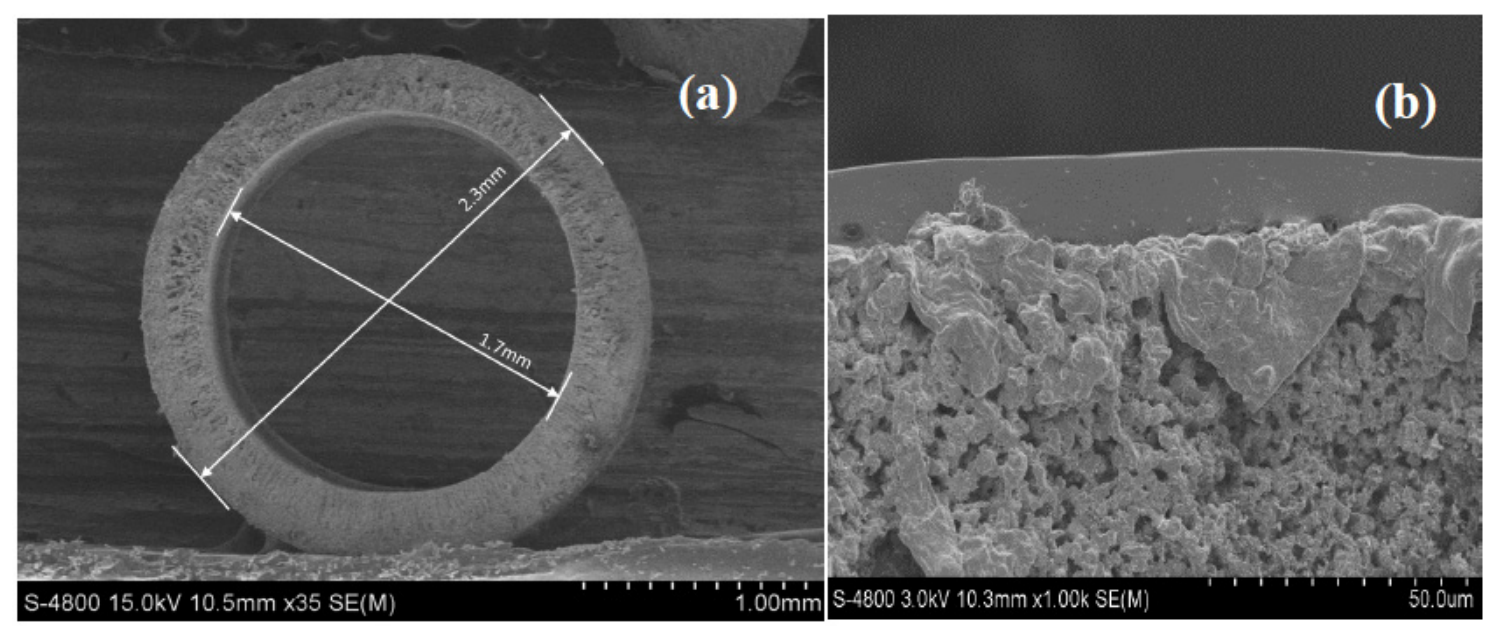

Figure 4: SEM images of the $\mathrm{Al}_{2} \mathrm{O}_{3}$ catalytic hollow fibre membranes with PDMS coating (a) cross-sectional; (b) outer edge. 


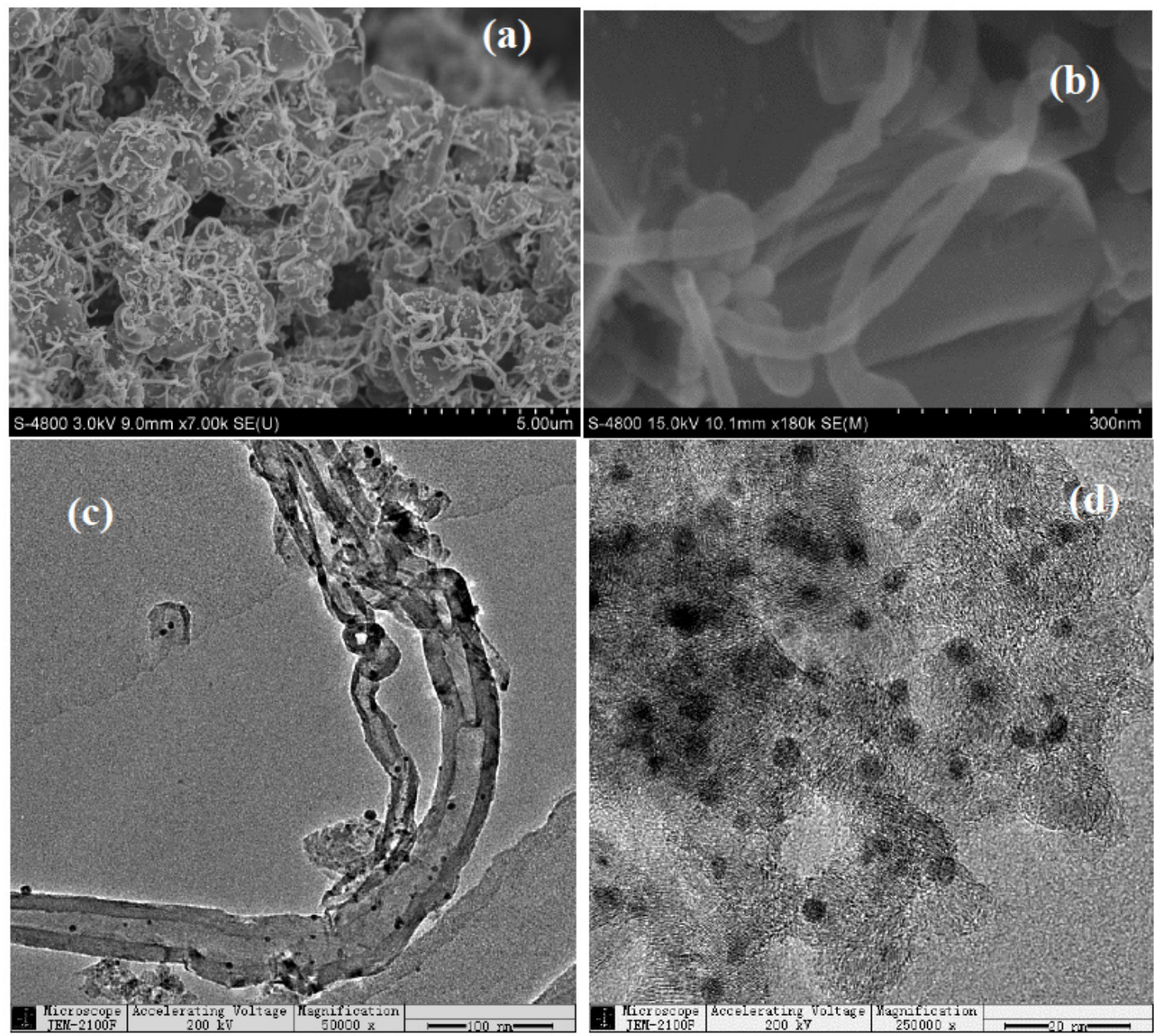

Figure 5: Images of the carbon nanotubes formed in the hollow fibre membrane pores: (a) SEM with low magnification; (b) SEM with high magnification; (c) TEM image; and (d) Pd catalyst distribution on the CNTs.

operating conditions, with which the nitrite removal can be calculated.

\subsubsection{Catalytic Effect of the Deposited Hollow Fibre Membranes}

Figure 6 illustrates the catalytic effect of deposited hollow fibre membranes on the nitrite removal. As can be seen, the carbon-deposited hollow fibre membranes obtained by the carbonization of glucose exhibited little catalytic activity to the hydrogenation reduction of nitrite (line (a)), while the Pd-CNTs-deposited hollow fibre membranes demonstrated around $29.0 \%$ nitrite removal after $460 \mathrm{~min}$, as shown by line (c) in the figure. Unexpected is that the CNTs-deposited hollow fibres without $\mathrm{Pd}$ catalyst loading also exhibited catalytic activity to nitrite hydrogenation. This may be attributed to the existence of iron particles left in the hollow fibres, which had been confirmed by the EDX measurement. The catalytic activity of iron and CNTs to the nitrite hydrogenation was also reported in literatures $[17,18]$, although it is inferior to that of the Pd particles.

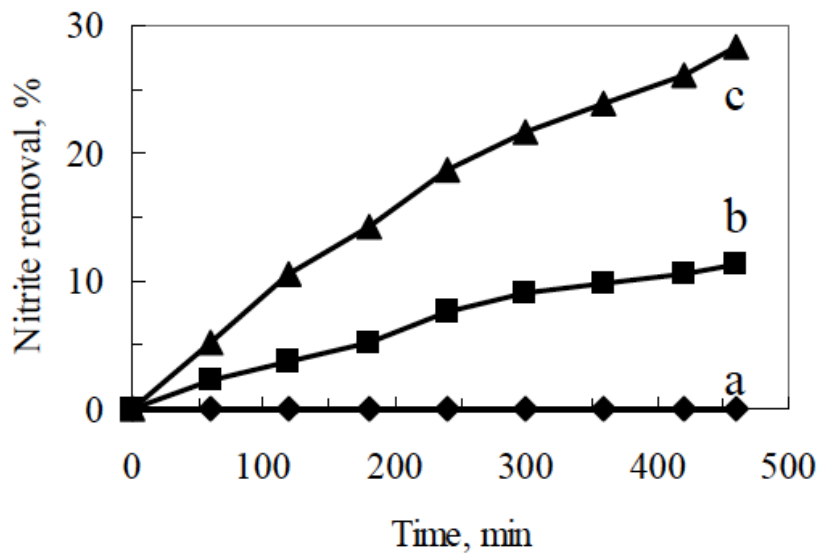

Figure 6: Effect of the catalyst on the reactor performance: (a) carbon by glucose carbonization; (b) CNTs by methane decomposition; (c) $\mathrm{Pd}$ deposited on the CNTs $\left(\mathrm{T}=25^{\circ} \mathrm{C}\right.$, $\mathrm{C}_{0}=18.96,18.68,18.82 \mathrm{mg} \mathrm{L}^{-1}$ for (a), (b) and (c), respectively). 


\subsubsection{Effect of Initial Nitrite Concentration}

Figure 7 shows the nitrite removal as a function of operation time as the initial nitrite concentration increased from $18.8 \mathrm{mg} \mathrm{L}^{-1}$ to $80.1 \mathrm{mg} \mathrm{L}^{-1}$. As can be seen, the nitrite removal decreased with increasing the initial nitrite concentration. However, the reaction rate of hydrogenation of $\mathrm{NO}_{2}{ }^{-}$, which can be evaluated by the multiple of initial concentration with nitrite conversion $\left(\mathrm{C}_{0}{ }^{*} \mathrm{X}\right)$, actually increased with the initial nitrite concentration. For example, the net decreases in the nitrite concentration after 460 min operation were $6.05 \mathrm{mg} \mathrm{L}^{-1}, 8.02 \mathrm{mg} \mathrm{L}^{-1}, 9.00 \mathrm{mg} \mathrm{L}^{-1}$ and $10.02 \mathrm{mg} \mathrm{L}^{-1}$ with respect to the initial nitrite concentrations of 18.8 $\mathrm{mg} \mathrm{L}^{-1}, 39.4 \mathrm{mg} \mathrm{L}^{-1}, 62.8 \mathrm{mg} \mathrm{L}^{-1}$ and $80.1 \mathrm{mg} \mathrm{L}^{-1}$, respectively. For the $62.8 \mathrm{mg} \mathrm{L}^{-1}$ initial nitrite concentration system, the average reaction rate was 0.028 and $0.023 \mathrm{mg} \mathrm{L}^{-1} \mathrm{~min}^{-1}$ over the reaction time of 60 and $180 \mathrm{~min}$, respectively. This agrees well with the mass action law.

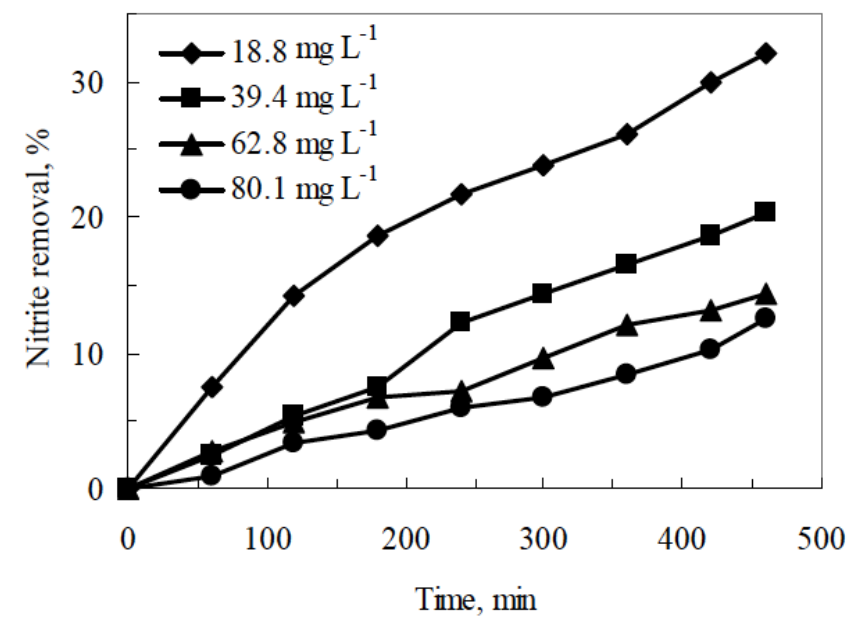

Figure 7: Effect of the initial concentration on the nitrite removal $\left(T=25^{\circ} \mathrm{C}\right.$, hydrogen feed).

\subsubsection{Effect of Operation Temperature}

The operation temperature was controlled by placing both the reactor and the feed tank in a thermostatic water bath. The temperature rise due to the reaction heat could be neglected because the nitrite concentration was low (about $21.5 \mathrm{mgL}^{-1}$ ) during the whole operation. Figure 8 shows the nitrite removal as a function of operation time at different operation temperatures. As is expected, the nitrite reduction rate increased with increasing the operation temperature. For instance, during the operation period of $540 \mathrm{~min}$, the nitrite removals reached $19.76 \%$ at $10^{\circ} \mathrm{C}, 21.60 \%$ at $20^{\circ} \mathrm{C}, 26.66 \%$ at $30^{\circ} \mathrm{C}$ and $30.76 \%$ at $40^{\circ} \mathrm{C}$, respectively. This obvious elevation in nitrite removal can be attributed to both the promoted reaction kinetics and the improved diffusion flux of the reactants, which have a positive effect on the decrement of diffusion resistance for both hydrogen and nitrite ions in the microchannels.

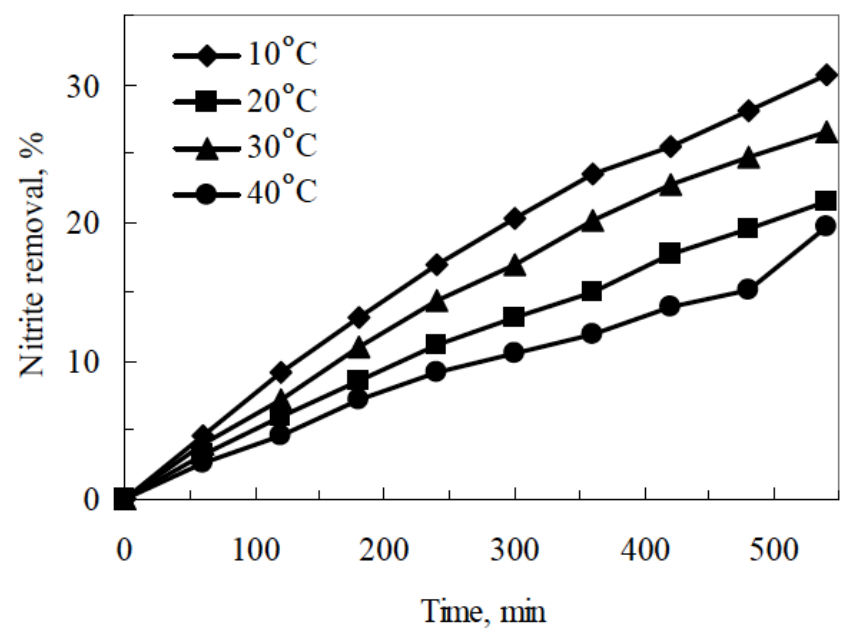

Figure 8: Effect of the operation temperature on the nitrite removal $\left(\mathrm{C}_{0}=21.5 \mathrm{mg} \mathrm{L}^{-1}\right)$.

\subsubsection{Effect of the Hydrogen Concentration in Gas Feed}

Figure 9 shows the effect of hydrogen feed concentration on the nitrite reduction performance. As can be seen, the reduction rate of $\mathrm{NO}_{2}^{-}$in the reactor increased as the hydrogen concentration in gas feed was increased from zero to $50 \%$. For example, the nitrite removal with $5 \%$ hydrogen feed concentration was $17.67 \%$ during the operation period of $480 \mathrm{~min}$. When the percentage of hydrogen was increased to $50 \%$, the nitrite removal increased to $32 \%$. However, the nitrite removal hardly changed as the hydrogen feed concentration was further raised from $50 \%$ to $100 \%$. This implies that the hydrogenation of nitrite over the Pd-CNTs catalyst may follow the LangmuirHinshelwood mechanism with respect to the hydrogen adsorption [1]. At low hydrogen concentrations, the hydrogenation rate is highly dependent on the hydrogen concentration but independent of the hydrogen concentration when the hydrogen concentration is high. An unexpected result is that the nitrite removal still reached $5.15 \%$ during the operation period of 480 min even no hydrogen was fed into the reactor. This is because hydrogen could be possibly stored with the formation of metal hydrides when exposed to hydrogen gas during the reduction process [18]. During the $\mathrm{NO}_{2}{ }^{-}$hydrogenation, the Pd-hydrides might act as both catalyst and hydrogen source to promote the hydrogenation of nitrite. This phenomenon was also observed and reported by Snijder et al. [19]. 


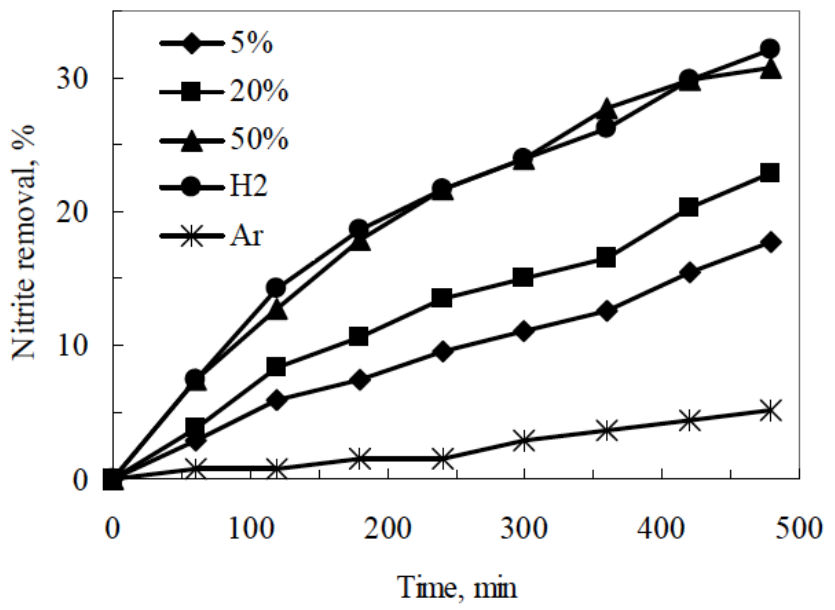

Figure 9: Effect of hydrogen feed concentration on the nitrite removal $\left(T=25^{\circ} \mathrm{C} ; C_{0}=19.1 \mathrm{mg} \mathrm{L}^{-1}\right)$.

\section{CONCLUSIONS}

Pd-CNTs loaded $\mathrm{Al}_{2} \mathrm{O}_{3}$ catalytic hollow fibre membranes have been prepared by the phase inversion and sintering technique followed by CNTs formation and Pd deposition. The resultant hollow fibre membranes exhibited high catalytic activity to the hydrogenation reduction of nitrites in aqueous solution. The nitrite removal in the hollow fibre membrane reactors increases with the operation temperature and the hydrogen feed concentration at lower hydrogen partial pressures, but the influence is very marginal when the hydrogen feed concentration is higher than $50 \%$. A higher nitrite concentration favors the nitrite hydrogenation reaction but the nitrite removal efficiency reaches maximum to process these nitrite contaminates at low concentrations.

\section{ACKNOWLEDGEMENTS}

The authors gratefully acknowledge the research funding provided by the National Natural Science Foundation of China (NNSFC, No.21176187), the Research Fund for the Doctoral Program of Higher Education of China (RFDP 20131201110007) and the Program for Changjiang Scholars and Innovative Research Team in University (PCSIRT) of Ministry of Education of China (Grand no. IRT13084).

\section{REFERENCES}

[1] Chinthaginjala JK, Lefferts L. Support effect on selectivity of nitrite reduction in water. Appl Catal B: Environ 2010; 101: 144-49. http://dx.doi.org/10.1016/j.apcatb.2010.09.023

[2] Pintar A, Bercic G, Levec J. Catalytic liquid-phase nitrite reduction: kinetics and catalyst deactivation. AIChE J 1998; 44: 2280-92.

http://dx.doi.org/10.1002/aic.690441017
Hoerold S, Vorlop KD, Tacke T, Sell M. Development of catalysts for selective nitrate and nitrite removal from drinking water Catals Today 1993; 17: 21-30. http://dx.doi.org/10.1016/0920-5861(93)80004-K

[4] Strukul G, Pinna F, Marella M, Meregalli L, Tomaselli M. Solgel palladium catalysts for nitrate and nitrite removal from drinking water Catal Today 1996; 27: 209-14. http://dx.doi.org/10.1016/0920-5861(95)00189-1

[5] Ebbesen SD, Mojet BL, Lefferts L. In situ ATR-IR study of nitrite hydrogenation over $\mathrm{Pd} / \mathrm{Al}_{2} \mathrm{O}_{3}$. J Catal 2008; 256: 15-23. http://dx.doi.org/10.1016/i.jcat.2008.02.013

[6] Chinthaginjala JK, Seshan K, Lefferts L. Preparation and application of carbon-nanofiber based microstructured materials as catalyst supports. Ind Eng Chem Res 2007; 46: 3968-78 http://dx.doi.org/10.1021/ie061394r

[7] Chinthaginjala JK, Bitter JH, Lefferts L. Thin layer of carbonnano-fibers (CNFs) as catalyst support for fast mass transfer in hydrogenation of nitrite. Appl Catal A: Gen 2010; 383: 2432.

http://dx.doi.org/10.1016/j.apcata.2010.05.013

[8] Reif M, Dittmeyer R. Porous, catalytically active ceramic membranes for gas-liquid reactions: a comparison between catalytic diffuser and forced through flow concept. Catal Today 2003; 82: 3-14 http://dx.doi.org/10.1016/S0920-5861(03)00197-4

[9] Ilinitch OM, Cuperus FP, Nosova LV, Gribov EN. Catalytic membrane in reduction of aqueous nitrates: operational principles and catalytic performance. Catal Today 2000; 56 : 137-45.

http://dx.doi.org/10.1016/S0920-5861(99)00270-9

[10] Tan X, Liu S, Li K. Preparation and characterization of inorganic hollow fiber membranes. J Membr Sci 2001; 188 : 87-95. http://dx.doi.org/10.1016/S0376-7388(01)00369-6

[11] Tan $X$, Liu Y, Li K. Preparation of $\mathrm{La}_{0.6} \mathrm{Sr}_{0.4} \mathrm{Co}_{0.2} \mathrm{Fe}_{0.8} \mathrm{O}_{3-\delta}$ hollow fiber membranes for oxygen production by a phaseinversion/sintering technique. Ind Eng Chem Res 2005; 44 61-66. http://dx.doi.org/10.1021/ie040179c

[12] Yan J, Zhu L, Luo Z, Huang Y, Tang H, Chen M. Oxidative decomposition of organic pollutants by using persulfate with ferrous hydroxide colloids as efficient heterogeneous activator. Separation Purification Technol 2013; 106: 8-14. http://dx.doi.org/10.1016/i.seppur.2012.12.012

[13] Pinilla JL, Utrilla R, Karn RK, Suelves I, Lázaro MJ, Moliner $R$, García AB, Rouzaud JN. High temperature iron-based catalysts for hydrogen and nanostructured carbon production by methane decomposition. Int J Hydrogen Energy 2011; 36 : $7832-43$ http://dx.doi.org/10.1016/j.ijhydene.2011.01.184

[14] Torres D, Pinilla JL, Lázaro MJ, Moliner R, Suelves I. Hydrogen and multiwall carbon nanotubes production by catalytic decomposition of methane: Thermogravimetric analysis and scaling-up of Fe-Mo catalysts. Int J Hydrogen Energy 2014; 39: 3698-709.

http://dx.doi.org/10.1016/j.ijhydene.2013.12.127

[15] Douven S, Pirard SL, Heyen G, Toye D, Pirard J-P. Kinetic study of double-walled carbon nanotube synthesis by catalytic chemical vapour deposition over an $\mathrm{Fe}-\mathrm{Mo} / \mathrm{MgO}$ catalyst using methane as the carbon source. Chem Eng $J$ 2011; 175: 396-407. http://dx.doi.org/10.1016/j.cej.2011.08.066

[16] Bahrami B, Khodadadi A, Mortazavi Y, Esmaieli M. Short time synthesis of high quality carbon nanotubes with high rates by CVD of methane on continuously emerged iron nanoparticles. Appl Surf Sci 2011; 257: 9710-16. http://dx.doi.org/10.1016/j.apsusc.2011.05.086 
[17] $\mathrm{Hu} \mathrm{H}-\mathrm{Y}$, Goto N, Fujie K. Effect of $\mathrm{pH}$ on the reduction of nitrite in water by metallic iron. Water Res 2001; 35: 2789-93. http://dx.doi.org/10.1016/S0043-1354(00)00570-4

[18] Aran HC, Pacheco Benito S, Luiten-Olieman MWJ, Er S, Wessling M, Lefferts L, Benes NE, Lammertink RGH. Carbon nanofibers in catalytic membrane microreactors. J Membr Sci 2011; 381: 244-50.

http://dx.doi.org/10.1016/j.memsci.2011.07.037
[19] Snijder ED, Versteeg GF, Van Swaaij WPM. Hydrogenation of cyclohexene with $\mathrm{LaNi}_{5-\mathrm{x}} \mathrm{Al}_{x} \mathrm{H}_{n}$ metal hydrides suspended in cyclohexane or ethanol. Chem Eng Sci 1993; 48: 2429-41. http://dx.doi.org/10.1016/0009-2509(93)81064-3 